\title{
Gestão participativa no comércio de animais aquáticos ornamentais (ensaio)
}

\section{Participatory management in trade of ornamental aquatic animals}

\section{Resumo}

Há tempos existem lacunas na pesca e aquicultura ornamental em sua legislação ambiental e sanitária. Com o objetivo de abrir um canal de diálogo entre as instituições públicas e os representantes do setor foi realizado nos dias 28 e 29 de junho de 2011 no CRMV-SP o “I Workshop de Gestão Participativa no Comércio de Peixes Ornamentais". Foram expostas as principais dificuldades do setor e a partir dos debates foi produzida uma moção, encaminhada aos participantes e às instituições. Acreditamos que estas iniciativas colaboram para o bom desenvolvimento do setor, considerando que todos têm como objetivos o bem estar dos animais, a saúde pública e a conservação do meio ambiente.

\section{Summary}

For a long time ornamental fishery and aquaculture laws were not made to address environmental and health matters. Aiming to open a channel of dialogue between public institutions and industry representatives, was conducted the "I Workshop in Participative Management in the Ornamental Fishery Sector" was held at CRMV-SP on June 28 and 29, 2011. The greatest difficulty of the sector were exposed and at the end of the meeting, a document was produced and sent to the participants with the main topics that were brought up during the Workshop. We believe that this initiative contributed to good development of the sector, with the animal welfare, the public health and the environment conservation. 
Ana Paula de Araujo ${ }^{1}$

Felipe Weber Mendonça Santos²

Sheila Pincinato 3

Jeanne Gomes da Silva ${ }^{4}$

Membro da Comissão Técnica de Aquicultura do Conselho Regional de Medicina Veterinária e Zootecnia do Estado de São Paulo / CRMV-SP

Rua Vieira de Morais, 1201,Campo Belo

04617-014 - São Paulo, SP.

= +55 11 9-9291-4143

受apaula@acquapiscis.com.br.

\section{Palavras-chave}

Aquariofilia. Regulamentação. Sanidade. Gestão participativa.

\section{Keywords}

Aquariophily. Regulation. Sanity. Participatory management.

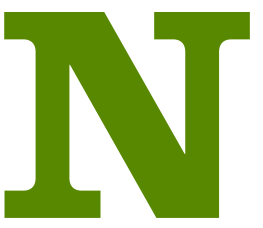

o Brasil a atividade de aquariofilia surgiu no Rio de Janeiro em 1922 durante a realização da Exposição da Independência nos pavilhões construídos pelo Governo Federal, transferida para a antiga Universidade do Brasil a partir da década de 1980 (LIMA; BERNARDINO; PROENÇA, 2001).

A produção de peixes ornamentais marinhos e continentais é considerada um rentável agronegócio. No Brasil, uma piscicultura ornamental bem administrada, com sistema intensivo em tanques de pequeno volume em ambiente controlado, pode gerar uma receita bruta de $\mathrm{R} \$ 30.000,00$ por hectare, com base em dados de produção de Betta splendens (RIBEIRO, 2008).

Atualmente o setor de aquicultura e comércio de organismos aquáticos com fins ornamentais e de aquariofilia é um setor que movimenta milhões de dólares anualmente, tendo a pesca extrativista continental e marinha predominante na região norte e nordeste respectivamente. A região sudeste caracteriza-se por ser um pólo de importação de organismos aquáticos e de insumos para a cadeia produtiva, sendo também representativo em termos de aquiculturas,

1 Médica Veterinária. Acquapiscis Consultoria e Medicina Veterinária em Aquicultura. Membro da Comissão Técnica de Aquicultura do Conselho Regional de Medicina Veterinária e Zootecnia do Estado de São Paulo / CRMV-SP.

2 Engenheiro de Aquicultura. Coordenador de Registro e Licenças da Pesca Artesanal, Ornamental e Industrial / CGRPC / SEMOC / Ministério da Pesca e Aquicultura / MPA.

3 Médica Veterinária. Assessoria Técnica Médico-Veterinária / CRMV-SP.

4 Engenheira de Pesca. Chefe de Divisão da Coordenação de Planejamento e Ordenamento da Pesca Artesanal Continental / CGPAC Secretaria de Planejamento e Ordenamento da Pesca / SEPOP / Ministério da Pesca e Aquicultura / MPA. 
com destaque para o Estado de Minas Gerais, especificamente o município de Muriaé (VIDAL, 2002).

Segundo estatísticas do IBAMA, em 2007 só o estado do Amazonas exportou US\$3.829.085,65 em peixes ornamentais continentais, sendo o total de exportações brasileiras de US\$ 6.000.846,37 neste mesmo ano.

A atividade pesqueira no Brasil tem historicamente uma trajetória complexa, pois sua regulamentação passou por diversas alterações nas atribuições públicas ao longo das últimas décadas. O desenvolvimento da aquicultura neste cenário é recente, assim como a organização do setor e elaboração de legislação sanitária e ambiental que o contemple, como, por exemplo, a obrigatoriedade de quarentena em importações, regulamentada pela Instrução Normativa/IN no 18 de 13/05/2008 do MAPA (BRASIL, 2008), sendo que as Licenças de Operação atualmente são concedidas através de vistorias realizadas pelo MPA. Porém muitos outros aspectos de sua regulamentação, por meio de legislações específicas, ainda não foram contemplados ou são dificultados, como as questões envolvendo a comercialização dos invertebrados ornamentais nativos, as licenças ambientais, a aquicultura de espécies nativas, etc.

Atualmente no Brasil, muitos estabelecimentos de comércio varejista e de produção de organismos aquáticos ornamentais atuam de maneira informal, principalmente em função das dificuldades na obtenção de licenças ambientais, somando-se ao fato de que, até o momento, existem poucos profissionais atuando nesta área. Isso também se relaciona ao fato de durante muito tempo a aquicultura ter sido um segmento em saúde animal pouco contemplado pela medicina veterinária e zootecnia, em relação aos avanços em áreas como, por exemplo, clínica de pequenos animais ou produção pecuária bovina, suína ou de aves (ARAUJO; PÉREZ, 2005).

A demanda por invertebrados aquáticos, característica deste mercado, o torna mais complexo, visto que estes animais possuem pouca expressão dentro das atividades de pesquisa em nível nacional e internacional. Neste caso, atualmente a legislação brasileira permite sua importação, porém o extrativismo e o cultivo de espécies aquáticas nativas ainda não foram regulamentados (IBAMA, 2007; RIBEIRO; LIMA; FERNANDES, 2010).

Estes pontos têm reflexos em diversos âmbitos que cercam a aquicultura, como na solicitação de licenças para captura de matrizes para reprodução, na pouca disponibilidade de terapêuticos e imunoestimulantes, na formulação de protocolos de manejo e de medidas de biossegurança, nas escassas produções bibliográficas em manejo, patologia e fisiologia de espécies aquáticas nativas e também nos poucos diagnósticos das doenças existentes em relação a outras espécies de produção com fins alimentares.
O uso de drogas terapêuticas em peixes é dificultado em função da farmacocinética em cada espécie e pela questão dos resíduos para o consumo humano, pouco estudado nas espécies aquáticas nativas, entre outros fatores. Estas questões atualmente não estão esclarecidas no cenário nacional, porém o uso de terapêuticos nesta atividade é uma necessidade antiga e real, sendo muitas vezes executado de forma empírica e clandestina, pois atualmente no Brasil existe apenas um medicamento registrado para uso em peixes (BRASIL/MAPA, 2009).

Neste panorama, deve ser considerado que na cadeia produtiva e de distribuição de animais aquáticos ornamentais, existem peculiaridades que os distinguem do mercado de peixes de corte que devem ser consideradas e são apresentadas no quadro 1 .

A legislação sanitária e ambiental relacionada aos animais aquáticos deve contemplar algumas destas peculiaridades inerentes às finalidades dos animais. Mas por outro lado, epidemiologicamente, um peixe ornamental doente introduzido em uma aquicultura oferece o mesmo risco que um peixe de corte doente introduzido num plantel, quando considerado o trânsito e a produção em zona rural.

Para auxiliar no processo de legalização dos aquicultores brasileiros, o MPA publicou a IN no 06/2011 (BRASIL, 2011), que trouxe os novos procedimentos do Registro Geral da Atividade Pesqueira- RGP, na categoria Aquicultor. Com a publicação desta norma, o MPA passou a ser a porta de entrada do aquicultor no processo de legalização, onde o interessado, antes de buscar o órgão ambiental Estadual responsável pelo Licenciamento Ambiental, realiza o Registro de Aquicultor on-line (www.mpa.gov.br). Após isso, o interessado solicita sua Licença Ambiental no órgão competente no seu Estado. Após a emissão desta, retorna a plataforma de Registro do MPA para ingressar os dados de sua Licença Ambiental para emissão da Licença de Aquicultor. Essas modificações realizadas foram de suma importância, pois o MPA passou a acompanhar o processo de legalização junto aos órgãos ambientais Estaduais, sendo que mensalmente é emitido relatório com o número de registros e licenças emitidas, permitindo ao MPA iniciar um diálogo com os órgãos ambientais Estaduais a fim de estimular a legalização da atividade aquícola.

A divisão de responsabilidades e de ações entre governo e sociedade tem possibilitado a construção de um novo espaço público, permitindo um novo papel a ser exercido pelos movimentos oriundos da sociedade civil. Isso porque os diversos segmentos e reorganizações sociais passam a fazer parte na definição da agenda do governo, direcionando as ações a serem priorizadas, tendo em vista uma maior adequação entre demandas sociais e políticas públicas (CRUZ, 2008). 


\begin{tabular}{|c|c|c|}
\hline Finalidade & - Alimento humano e ração animal. & - Mascotes, lazer. \\
\hline Origem & $\begin{array}{l}\text { - Reproduzidos em cativeiro. } \\
\text { - Nacionais. }\end{array}$ & $\begin{array}{l}\text { - Selvagens (pesca) ou reproduzidos em cativeiro. } \\
\text { - Importados ou nacionais. }\end{array}$ \\
\hline Tipo de comercialização & - Comercializados em lotes ou milheiros. & - Comercializados individualmente no varejo. \\
\hline Natureza das espécies & - Predominantemente exóticos & - Nativos e exóticos. \\
\hline Localização & - Presentes em área rural. & - Presentes principalmente em zonas urbanas. \\
\hline Regulamentação & - Escassa. & - Escassa. \\
\hline Importação & - Dificultada. & - Permitida. \\
\hline Abastecimento de água & - Corpos d'água naturais. & $\begin{array}{l}\text { - Rede pública em lojas. } \\
\text { - Corpos d'água naturais (área rural). }\end{array}$ \\
\hline Descarte da água & - Corpos d'água naturais. & $\begin{array}{l}\text { - Rede pública de esgoto. } \\
\text { - Corpos d'água naturais. }\end{array}$ \\
\hline Tratamento da água & - Esporádico. & - Frequente em rede pública. \\
\hline $\begin{array}{l}\text { Presença de invertebrados com } \\
\text { interesse comercial }\end{array}$ & - Apenas em sistemas consorciados (carcinocultura). & - Presente. \\
\hline Fluxo de água & - Contínuo da maioria das vezes. & - Sistemas fechados (recirculação). \\
\hline Uso de drogas & - Presente. & - Presente. \\
\hline
\end{tabular}

QUADRO 1 - Características do mercado peixes ornamentais e do mercado de peixes de corte oriundos de piscicultura

\section{Objetivos}

O objetivo deste trabalho foi abrir um canal de diálogo entre representantes do mercado de animais aquáticos ornamentais no Estado de São Paulo e representantes dos órgãos reguladores desta cadeia produtiva, de forma que todos pudessem expor suas demandas e justificativas, assim como aumentar sua participação nas decisões da esfera pública em busca de um entendimento comum. Também teve a finalidade de produzir um documento para ser encaminhado formalmente àquelas instituições da esfera pública, acordado pela maioria e contendo as principais demandas e determinadas proposições elaboradas durante o workshop.

\section{Métodos}

Houve duas etapas nos processos de discussão. $\mathrm{Na}$ primeira etapa foram realizadas três reuniões na sede do CRMV-SP. Nas oportunidades, com a presença do Presidente do CRMV-SP, compareceram duas associações representativas do setor de aquariofilia no Estado de São Paulo - a Associação Brasileira de Lojas de Aquariofilia - ABLA, e Associação Brasileira de Aquaristas - ABRAQUA, além da Comissão Técnica de Aquicultura e a Comissão de Responsabilidade Técnica do CRMV-SP. Nesta etapa foram levantadas as principais dificuldades e demandas do setor, principalmente no que concerne à legislação sanitária e ambiental que regula a atividade de aquicultura e comércio de animais aquáticos ornamentais.

$\mathrm{Na}$ segunda etapa realizou-se o workshop "Gestão Participativa do Comércio de Peixes Ornamentais", que ocorreu nos dias 28 e 29 de junho de 2011, na sede do CRMV-SP. Neste evento os participantes da mesa, composta pela ABLA, ABRAQUA, Instituições Reguladoras (MAPA, MPA, IBAMA, CRMV-SP e Secretaria da Agricultura e Abastecimento do Estado de São Paulo SAA-SP), além de aquicultores, lojistas, pesquisadores e profissionais autônomos.

No primeiro dia do workshop foram realizadas apresentações que abordaram assuntos como as principais demandas do setor de comércio, dados atualizados das exportações e importações de organismos aquáticos com fins ornamentais no Brasil, epidemiologia em peixes, zoonoses transmitidas por peixes ornamentais, o papel do Responsável Técnico e sua formação profissional para atuar no mercado, as dificuldades nos processos de importação e exportação e toda a legislação ambiental e sanitária que envolve a atividade.

No segundo dia os participantes foram divididos em dois grupos, onde um grupo discutiu a respeito das questões de ordem sanitária e o outro as questões de ordem ambiental. Os grupos elaboraram proposições para cada demanda, sendo então apresentadas aos demais participantes para aprovação e finalização do documento. 


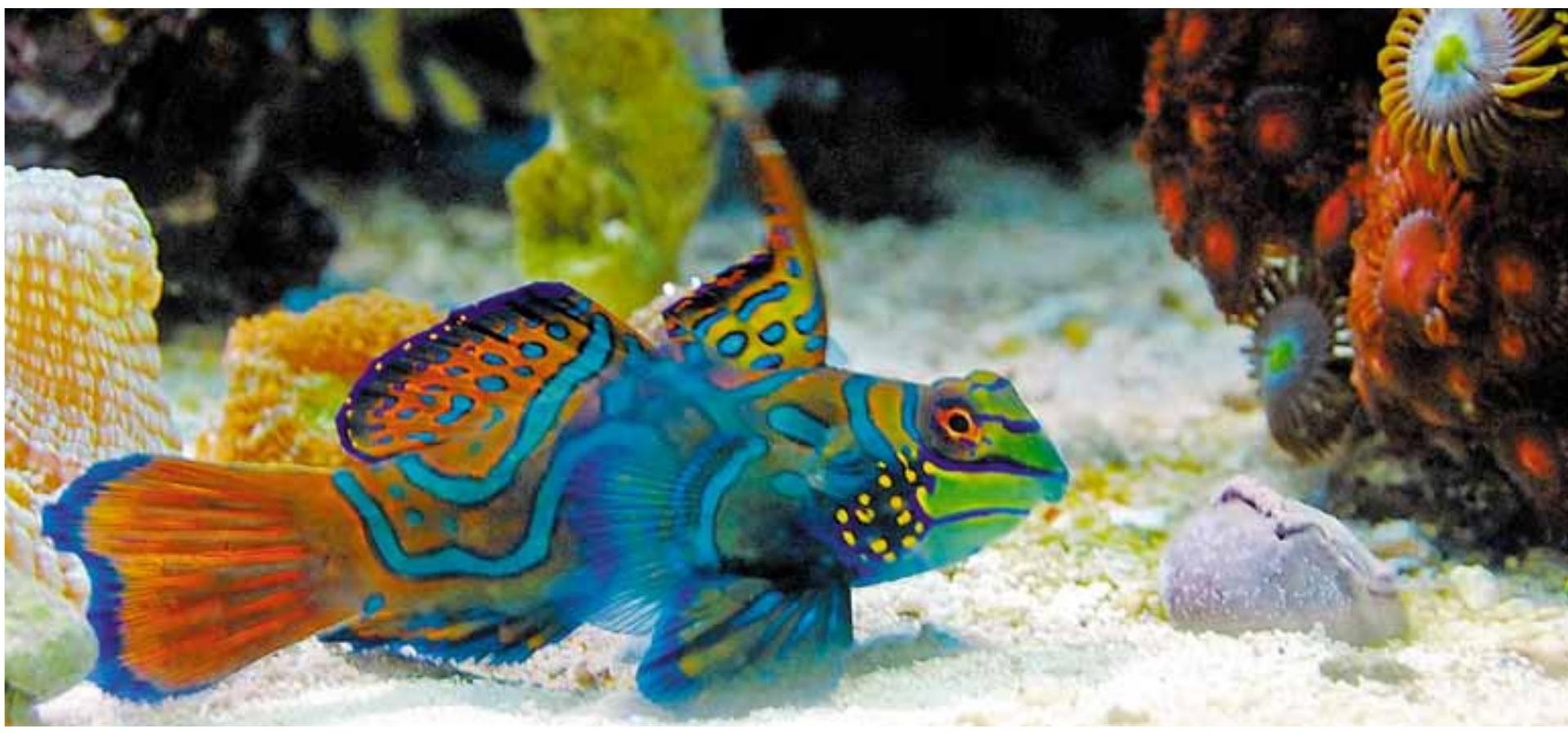

Mandarim azul (Synchiropus splendidus). Origem: Pacífico ocidental

\section{Resultados}

Em decorrência das proposições elaboradas foi gerada uma moção contendo as proposições e o histórico do evento, que foi encaminhada pelo CRMV-SP através do ofício no 0429/2011/ATMV/SP 29/07/2011 (SÃO PAULO, 2011) aos órgãos competentes em 16/08/2011. O referido ofício foi respondido pelo MPA também através dos ofícios $\mathrm{n}^{\circ}$ 272/2011 da Secretaria de Monitoramento e Controle/ SEMOC/MPA de 21/10/2011 e n 50/2011 da Coordenação Geral de Registro de Aquicultura/CGRA/Departamento de Registro da Pesca e Aquicultura/DRPA/SEMOC/MPA de 26/10/2011 (BRASIL, 2011). Abaixo se encontram os temas debatidos, as proposições sugeridas durante o encontro e as manifestações do MPA.

- Tema 1 - Guia de Trânsito Animal - GTA / Guia de Trânsito de Peixes Ornamentais - GTPON. Motivo: A obrigatoriedade do uso de duas guias de trânsito uma com informações de interesse sanitário (BRASIL/ MAPA, IN. $n^{\circ}$ 18/2006) e outra com informações de interesse ambiental (IBAMA, IN. $n^{\circ}$ 89/2006) atrasa os trâmites de transporte. Proposição: Foi proposto que haja uma unificação das Guias, onde informações de ambas as naturezas estivessem contempladas num único documento com vias para ambos os órgãos requisitantes. Manifestação do MPA: Quanto a isso, o MPA explanou que atualmente está em discussão o Programa Nacional de Sanidade de Animais
Aquáticos, e manifestou ser viável otimização de ações regulatórias que atendam ao MPA e ao IBAMA.

- Tema 2- Morosidade na liberação de cargas para importação e exportação de animais aquáticos ornamentais no aeroporto. Motivo: Por motivos de horários de voos e ordem das cargas recebidas nos terminais, muitas vezes os animais importados não são liberados no dia da chegada. Porém para estes animais, que muitas vezes vêm de lugares longínquos como países asiáticos, o tempo de permanência embalados pode ser crucial para a higidez e sobrevivência dos animais, visto que estes estão limitados de oxigênio e água de boa qualidade. No processo de liberação de cargas diversos órgãos estão envolvidos, como MAPA, IBAMA, Empresa Brasileira de Infraestrutura Aeroportuária - INFRAERO e Receita Federal, e para cada um deles foi proposta uma sugestão. Proposições: Ao MAPA e ao MPA foi proposta a possibilidade de agendamento das cargas e a presença de uma equipe maior e bem treinada para $\mathrm{o}$ atendimento. À INFRAERO e à Receita Federal, na ausência de representantes, as questões relacionadas foram encaminhadas pelo representante da Comissão de Clientes do MAPA. A proposta foi a priorização do desembaraço das cargas vivas (LI antecipada) e o registro antecipado de carga em trânsito, já previsto na IN. $n^{\circ}$ 680/2006 da Secretaria da Receita 
Federal (BRASIL, 2006). O MPA se manifestou como favorável ao desenvolvimento de estratégias para flexibilizar a operacionalização do trânsito desde que cumpra a legislação em vigência. Também sugeriu que procedimentos para os referidos casos sejam apresentados pela Coordenação Geral de Vigilância Agropecuária - VIGIAGRO/DAS aos importadores e exportadores de peixes ornamentais.

- Tema 3 - Quarentena. Motivos: A quarentena durante a importação de peixes ornamentais foi um tema bastante discutido, e apresentou-se com certa rejeição por parte dos representantes do mercado, que em muitos casos a utilizam por obrigação legal. Foi exposto pelos representantes do mercado que há diferenças no rigor de fiscalização sanitária por parte do órgão competente (MPA) em diferentes Estados da Federação, o que, de acordo com os mesmos, é injusto para aqueles que seguem rigorosamente as normas estabelecidas. Neste sentido foi exposto aos participantes sua importância como uma ferramenta de proteção sanitária ao seu estabelecimento, ao seu mercado e à sanidade aquícola geral. Proposição: Foi definido que se cumpra a padronização de métodos para a fiscalização entre os diferentes Estados da Federação. Manifestação do MPA: O MPA esclareceu estar montando um cronograma de fiscalização in loco a todas as unidades de quarentena credenciadas, estabelecido para o final de 2011 e início de 2012, objetivando o alinhamento das exigências para o credenciamento das unidades quarentenárias em conformidade com a legislação.

- Tema 4 - Responsabilidade Técnica sanitária nos estabelecimentos. Motivos: Os estabelecimentos de aquicultura no Estado de São Paulo, incluindo lojas de aquário, devem ter um médico veterinário como RT do estabelecimento, de acordo com o Decreto Estadual $n^{\circ} 40.400$ de 24/10/1995 (SÃO PAULO, 1995). Porém $\mathrm{o}$ argumento debatido foi o pequeno número de profissionais especializados em organismos aquáticos ornamentais que atuam neste setor e o aumento de custos gerados por esta obrigatoriedade. Proposição: Propôs-se que um profissional pudesse atender um maior número de estabelecimentos através de Associações. Também que o CRMV-SP deixasse uma base de dados disponível dos profissionais treinados em manejo sanitário e patologia de peixes oferecidos pela instituição. Neste caso, embora exista um número máximo de estabelecimentos que um RT possa atuar, o CRMV-SP é favorável ao estudo de caso a caso, o que dependerá da localidade e porte dos estabelecimentos, assim não comprometendo a eficiência dos serviços. É importante destacar que a atual gestão, através da Comissão Técnica de Aquicultura do CRMV-SP, tem oferecido anualmente cursos de extensão em sanidade aquícola e em responsabilidade técnica para estabelecimentos de comércio de peixes ornamentais para profissionais e estudantes de medicina veterinária.

- Tema 5 - Uso e registro de medicamentos em aquariofilia. Motivo: Atualmente é bastante limitada a quantidade de drogas permitidas para uso em peixes. Proposição: Através das associações e com apoio do poder público (citou-se o MPA), poderia ser efetuado um levantamento epidemiológico das principais doenças no Brasil e um inventário das doenças para o desenvolvimento e liberação de medicamentos adequados à realidade da aquicultura com fins ornamentais. Manifestação do MPA: Com o intuito de disponibilizar mais opções de produtos veterinários para uso em aquicultura, o Ministério da Pesca e Aquicultura, solicitou ao Ministério da Agricultura Pecuária e Abastecimento a priorização na análise de processos de registro de produtos veterinários destinados a aquicultura que estão em análise naquele órgão (Ofício Conjunto $\mathrm{n}^{\circ}$ 01/2011 SEMOC/SEPOA/MPA de 27/04/2011) (BRASIL, 2011). Essa necessidade é crescente devido ao pleno desenvolvimento da atividade e ao reduzido número de medicamentos disponíveis, e no intuito de auxiliar nesse processo o MPA disponibilizou corpo técnico qualificado para auxílio à avaliação para o referido registro.

- Tema 6 - Regulamentação para doação, troca ou comércio de espécimes excedentes. Motivos: Em muitas ocasiões, os animais reproduzem-se nos aquários ou tanques particulares, podendo representar um desequilíbrio ao sistema (aquário) e/ou uma ameaça aos animais já existentes no sistema aquático. Este é o caso principalmente dos invertebrados, como corais e anêmonas. Nesta circunstância por que passa o aquarista não há alternativas formais para o encaminhamento deste excedente. Proposição: Regulamentação da possibilidade de entrega/devolução/renegociação dos animais aos lojistas, que teriam um local separado para os receber. Também se propôs a doação às instituições, como aquários públicos ou universidades. Foi citado o sacrifício dos animais excedentes, como corais e anêmonas. No caso de retorno às lojas, a questão cuja solução ficou em aberto foi como seria viabilizada a legalização da entrada dos animais junto aos lojistas. Quanto a este item ainda não se obteve retorno dos órgãos competentes. 


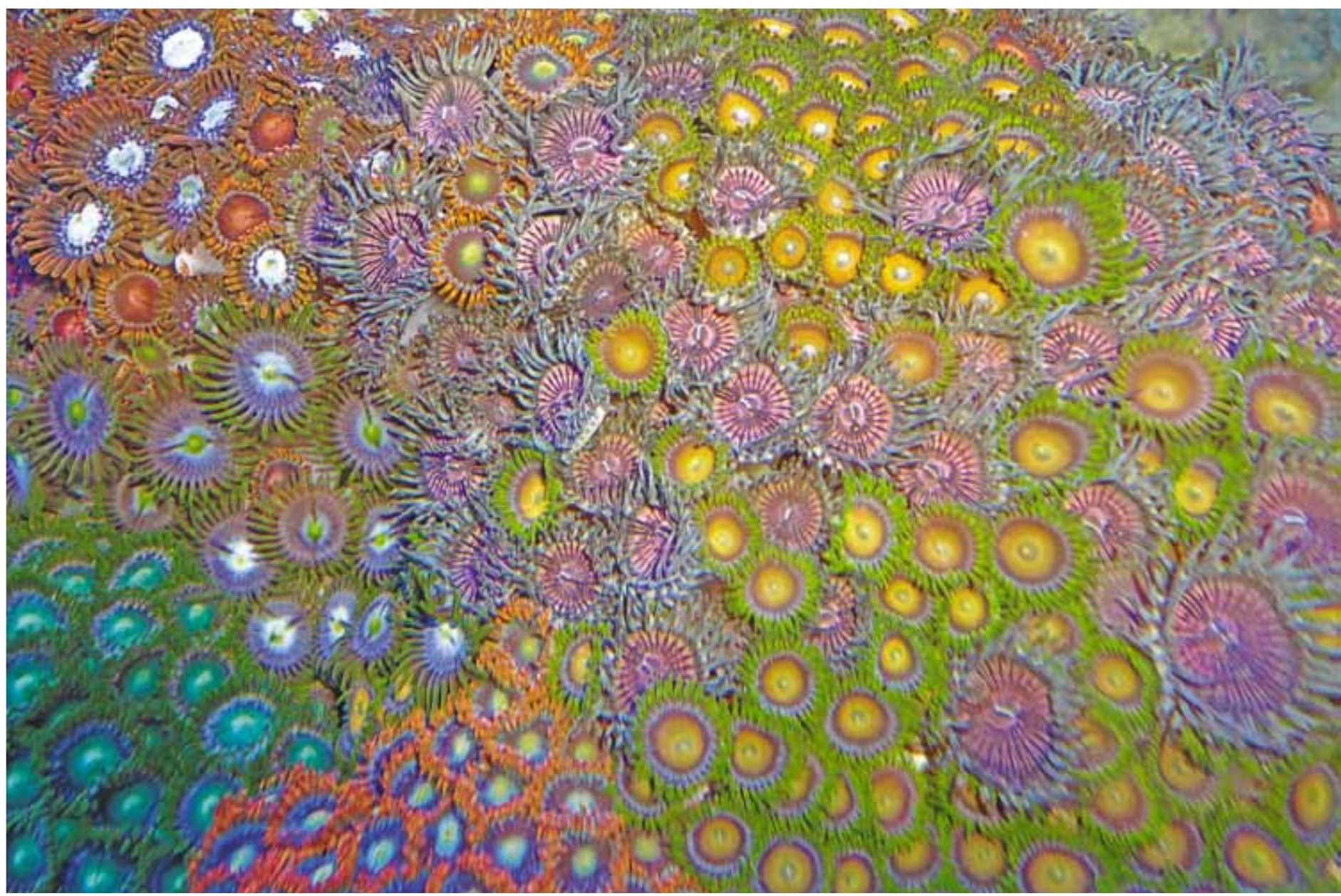

Zoanthus: gênero de invertebrado com ampla distribuição geográfica e de fácil reprodução, comumente

encontrado em aquários ornamentais marinhos decorados com corais vivos

- Tema 7 - Incentivo para a regularização dos membros da cadeia produtiva. Motivo: Atualmente grande parte dos estabelecimentos de aquicultura apresenta-se na informalidade. A dificuldade no Licenciamento Ambiental representa uma grande preocupação por parte dos aquicultores. Este fato compromete a certificação sanitária, o controle de doenças e a rastreabilidade dos animais. Proposição: Para mudar este quadro propôs-se que as Associações, em conjunto a outras instituições públicas, buscassem junto ao órgão Estadual de Meio Ambiente, alternativas no processo de Licenciamento Ambiental. Para o Estado de São Paulo se sugeriu a solicitação do MPA à Companhia de Saneamento Básico do Estado de São Paulo CETESB a inclusão do aquicultor urbano na lista de dispensa de Licenciamento Ambiental. Também se propôs a implementação de um marco zero para o cultivo de peixes ornamentais.
- Tema 8 - Revisão da legislação para exploração de substratos calcários. Motivo: Este item refere-se ao uso de esqueletos de plantas calcárias (halimeda) utilizada como substrato em aquários ornamentais marinhos. Foi esclarecido pelos representantes do IBAMA que já existe norma específica (IN IBAMA nº 89/2006), que permite este comércio.

- Tema 9 - Extrativismo e comércio de invertebrados. Motivo: Existe uma grande demanda por invertebrados aquáticos (crustáceos, celenterados, equinodermos) na aquariofilia marinha, pois são detritívoros e colaboram no equilíbrio do sistema aquático. Porém hoje não há regulamentação sobre este comércio em relação às espécies nativas. Proposição: Havendo o cumprimento das normativas vigentes sobre espécies em risco de extinção a captura seria permitida. Manifestação do MPA: Devido à necessidade eminente de revisão da legislação da pesca e aquicultura ornamental, o 
Ministro de Estado da Pesca e Aquicultura instituirá no primeiro semestre de 2012 um Grupo de Trabalho que subsidiará seus superiores sobre as discussões que serão provocadas com outros órgãos públicos federais, referentes à temática ornamental.

- Tema 10 - Facilitação do processo de captura de matrizes de espécies aquáticas com fins ornamentais. Motivo: A captura de matrizes de espécies para reprodução em cativeiro está atrelada ao modelo de autorização positivista utilizado pelo governo brasileiro o que impossibilita a liberação de licenças de captura de matrizes para espécies que não constem nestas listas positivas. Esta é uma demanda antiga do mercado e importante principalmente para as espécies em risco de extinção. Atualmente é mais fácil reproduzir espécies exóticas do que as espécies nativas e endêmicas. Proposição: Propôs-se que seja estabelecida pelos órgãos reguladores uma norma para a obtenção de licenças de captura de matrizes para aquicultura ornamental, incluindo as espécies que constam em normativas de espécies ameaçadas de extinção. Manifestação do MPA: Este assunto está elencado como um dos temas a serem discutidos pelo Grupo de Trabalho a ser instituído pelo MPA.

- Tema 11 - Revisão da IN IBAMA no 202/2008 referente aos organismos aquáticos ornamentais marinhos e estuarinos permitidos para importação. Motivo: Quanto a este item, foi informado que existe um processo de revisão da IN IBAMA no 202/2008 em vias de ser encaminhado ao MPA, para elaboração de uma Instrução Normativa interministerial entre o MPA e o MMA. Manifestação do MPA: Este assunto está elencado como um dos temas a serem discutidos pelo Grupo de Trabalho a ser instituído pelo MPA.

\section{Ações geradas a partir do Workshop}

Recentemente foi publicada a Instrução Normativa Interministerial MPA/MMA no 1 de 3 de janeiro de 2012 (BRASIL, 2012), que ampliou a lista de espécies de peixes nativos ou exóticos de águas continentais com finalidade ornamental ou de aquariofilia permitidos para captura e comercialização, o que também atende aos anseios do setor. Esta normativa incrementou, segundo relato dos exportadores em reunião realizada pelo MPA na cidade de Belém em 2012, em 400\% as exportações do Estado do Pará.

No início do ano de 2012, o MPA iniciou o trabalho junto aos aeroportos dos principais Estados da Federação por onde são importados e exportados animais aquáticos ornamentais. Foram realizadas reuniões nos Estados do
Amazonas, Pará, Ceará e São Paulo, estando previstos ainda os aeroportos do Rio de Janeiro, Pernambuco e Espírito Santo. No Estado do Amazonas, através de simples medidas operacionais, o tempo para o embarque dos peixes para exportação foi reduzido de $16 \mathrm{~h}$ para $4 \mathrm{~h}$, reduzido em $3 / 4$ do tempo, o que se traduz em redução do tempo total de trânsito dos peixes ornamentais e consequentes benefícios para o bem estar dos animais, manutenção de sua higidez até o destino e redução de prejuízos econômicos para o setor. Em Belém/PA (aeroporto responsável por $70 \%$ das exportações em termos de valor) foi finalizado e assinado o protocolo de procedimentos para exportação com as responsabilidades do exportador aos órgãos públicos envolvidos. Esse protocolo estabeleceu por meio de um fluxograma o prazo de 4 horas desde a chegada da carga até a sua liberação expedida pela Receita Federal à companhia aérea. Já em São Paulo/SP (predominantemente importador) as novas medidas, também acordadas em reuniões, estão na primeira fase de testes, com possíveis resultados de redução do tempo de desembaraço das cargas em curto prazo.

Além disso, recentemente e a pedido do excelentíssimo Ministro de Estado da Pesca e Aquicultura, foi instituído através da Portaria MPA n ${ }^{\circ}$ 156/2012 (BRASIL, 2012) o Grupo Técnico de Trabalho de Políticas de Pesca e Aquicultura Ornamentais, que conta com representantes da Secretaria de Monitoramento e Controle da Pesca e Aquicultura, Secretaria de Planejamento e Ordenamento da Pesca, Secretaria de Planejamento e Ordenamento da Aquicultura e Secretaria de Infraestrutura. Um dos objetivos do Grupo de Trabalho é levantar os subsídios necessários ao MPA para provocar a discussão de revisão das normas que atendam ao setor com responsabilidade ambiental.

Este órgão também realizou a indicação de um representante ao Comitê de Pesca e Aquicultura da Federação das Indústrias do Estado de São Paulo - FIESP no intuito de incluir as demandas do setor nos pleitos que estavam sendo realizados junto ao governo do Estado de São Paulo.

Outra ação positiva foi a realização de uma reunião entre a Coordenação Geral de Registro de Aquicultura e a Companhia de Tecnologia de Saneamento Ambiental de São Paulo - CETESB, a fim de solicitar àquele órgão o tratamento diferenciado aos aquicultores urbanos, pois estes utilizam água da companhia de água e pagam $100 \%$ de tratamento sobre a água utilizada. O MPA também assinalou a possibilidade de formalizar um termo de cooperação junto a CETESB a fim de compartilhar informações evitando a necessidade de o aquicultor realizar cadastro em ambos os órgãos, já que pela Lei no 11.959/2009 (BRASIL, 2009), este tem que realizar registro no MPA. 


\section{Conclusões}

Neste evento ficou evidente o quanto a aquicultura ornamental no Brasil ainda necessita progredir em seus aspectos técnicos e de regulamentação ambiental e sanitária.

A organização do setor da cadeia produtiva ainda é frágil e incipiente e muitos ainda possuem preocupações em se expor, pois a pouca orientação técnica e as dificuldades na aquisição de Licenciamento Ambiental são fatores limitantes e que tornam a atividade em muitos aspectos informal.

Porém a busca de consensos entre as instituições reguladoras e a cadeia produtiva é fundamental para que todos os atores envolvidos atinjam o grau de maturidade necessário para a superação de desafios, fortalecimento e crescimento da aquicultura e comércio de animais aquáticos com fins ornamentais e de aquariofilia no Brasil.

Um dos pontos mais discutidos pelos representantes do setor foi quanto à atuação do médico veterinário na área de peixes ornamentais. Foi discutida exaustivamente a atuação profissional, que, segundo os participantes, muitas vezes deixa a desejar em relação às necessidades práticas e objetivas dos estabelecimentos de aquicultura e comércio, como orientação de boas práticas de manejo, diagnóstico, terapêutica e todas as outras atribuições de um responsável técnico.

Quanto a esta questão os autores ressaltam que deva haver maior esforço e atenção no ensino da medicina veterinária sobre a área de aquicultura e sanidade de peixes, com consequências positivas para toda a cadeia produtiva. Desta forma poderá haver uma fase de real contribuição no que lhe compete, assim como ocorreu no passado em outras áreas de produção animal de sucesso no Brasil.

Por fim, os autores gostariam de compartilhar e deixar como exemplo este modelo de discussão em que ficou evidenciado o quanto pode ser atingido com os debates e a formalização das demandas, a organização do setor e a oportunidade de diálogo com as instituições reguladoras que trouxeram esclarecimentos e benefícios para os envolvidos, em diferentes níveis: técnico, produção, distribuição, comércio varejista e consumidor final.

\section{Agradecimentos}

Para a realização do evento os autores gostariam de agradecer o apoio e a participação do Dr. Francisco Cavalcanti de Almeida (Presidente do CRMV-SP), Dra. Agar Costa Alexandrino de Pérez (SAA/IP-SP), Dr. Alexandre Develey (CRT/CRMV-SP), Dr. Rui Donizete Teixeira (CGRA/ DRPA/SEMOC/MPA), Dr. Claudio Regis Depes (CDA/ SAA-SP), Dr. Augusto Pérez Montano (CTA/CRMV-SP), Dr. Roberto Takanobu Ishikawa (CTA/CRMV-SP),
Ricardo Ferreira Martins (Worldfish Peixes Ornamentais e Aquários/Comissão de Clientes do MAPA), Dra. Tatiana F. S. Pelucio (ATMV/CRMV-SP), Dra. Patrícia Pozzetti (SSA/ SFA/MAPA-SP), Dr. Carlos Alberto Diegues Fogaça (SSA/ SFA/MAPA-SP), Dr. Cleverson Freitas (SVA/GRU/DDA/ SFA/MAPA-SP), Dr. José de Barros Vieira (CDA/SAA-SP), Dr. João Batista Kochenborger Fernandes (UNESP/ Jaboticabal), Daniel Eduardo Visciano de Carvalho (NUFAP/SUPES/IBAMA-SP) e Luis Frosh (IBAMA-SP), além das Associações, pesquisadores e profissionais autônomos presentes no evento. Também agradecem a foto gentilmente cedida por Ricardo Paiva Rio.

\section{Referências}

ARAUJO. A. P.; PÉREZ, A. C. O médico veterinário e o comércio de peixes ornamentais. Revista de Educação Continuada CRMV-SP, São Paulo, v. 8, n. 2, p. 176-186, 2005.

BRASIL. CONSELHO FEDERAL DE MEDICINA VETERINÁRIA E ZOOTECNIA. Resolução n. 592, de 26 de junho de 1992. Enquadra as Entidades obrigadas a registro na Autarquia: CFMV-CRMVs, dá outras providências e revoga as Resoluções n ${ }^{\circ} \mathrm{S} 80 / 72 ; 182 / 76$; 248/79 e 580/91. Diário Oficial \{da\} República Federativa do Brasil. Brasília, DF, 27 out. 2009, Seção 1, p. 15089.

BRASIL. Lei $n^{\circ} 5.517$, de 23 de outubro de 1968. Dispõe sobre o exercício da profissão de Médico Veterinário e cria os Conselhos Federal e Regionais de Medicina Veterinária. Diário Oficial \{da\} República Federativa do Brasil, Poder Executivo, Brasília, DF, 25 out. 1968. Seção 1.

BRASIL. Lei $n^{\circ} 11.958$, de 26 de junho de 2009. Dispõe sobre a transformação da Secretaria Especial de Aquicultura e Pesca da Presidência da República em Ministério da Pesca e Aquicultura. Diário Oficial \{da\} República Federativa do Brasil, Poder Executivo, Brasilia, DF, 9 jun. 2009. Seção. 1, p. 01-02.

BRASIL. Lei $n^{\circ} 11.959$, de 29 de junho de 2009. Dispõe sobre a Política Nacional de Desenvolvimento Sustentável da Aquicultura e da Pesca. Diário Oficial \{da\} República Federativa do Brasil, Poder Executivo, Brasília, DF, 30 jun. 2009. Seção 1.

BRASIL. MINISTÉRIO DA AGRICULTURA, PECUÁRIA E ABASTECIMENTO. Secretaria de Defesa Agropecuária. Instrução Normativa $n^{\circ} 18$, de 18 jul. 2006. Regulamenta guia de transporte de animais Diário Oficial \{da\} República Federativa do Brasil. Brasília, DF, 20 jul. 2006.

BRASIL. MINISTÉRIO DA AGRICULTURA, PECUÁRIA E ABASTECIMENTO. Secretaria de Defesa Agropecuária. Instrução Normativa $n^{\circ} 18$, de 13 mai. 2008. Estabelece os procedimentos para importação de animais aquáticos para fins ornamentais e destinados à comercialização. Diário Oficial \{da\} República Federativa do Brasil. Brasília, DF, 14 maio 2008. Seção. 1, p. 13.

BRASIL. MINISTÉRIO DA AGRICULTURA, PECUÁRIA E ABASTECIMENTO. Coordenação de Fiscalização de Produtos Veterinários. Relatório de produtos com licença vigente. Disponível em: <http://www.agricultura.gov.br/arq_editor/file/ Registros_Autorizacao/listas\%20de\%20produtos/licen\%C3\%A7asvigentes\%209_03. pdf> Acesso em: 19 nov. 2012.

BRASIL. MINISTÉRIO DA FAZENDA. Secretaria da Receita Federal. Instrução Normativa SRF $n^{\circ} 608$, de 9 de janeiro de 2006. Dispõe sobre o Sistema Integrado de Pagamento de Impostos e Contribuições das Microempresas e das Empresas de Pequeno Porte (Simples). Diário Oficial \{da\} República Federativa do Brasil. Brasília, DF, 13 jan. 2006. 
BRASIL. MINISTÉRIO DA PESCA E AQUICULTURA. Ofício Conjunto n 01/2011 Secretaria de Monitoramento e Controle (SEMOC). Secretária de Planejamento e Ordenamento da Aquicultura/ SEPOA. Brasília, DF, 27 abr. 2011.

BRASIL. MINISTÉRIO DA PESCA E AQUICULTURA. Portaria $n^{\circ} 156$, de 6 de junho de 2012. Institui o Grupo Técnico de Trabalho de Políticas de Pesca e Aquicultura Ornamentais. Diário Oficial \{da\} República Federativa do Brasil. Brasilia, DF, 6 jun. 2012. Sec. 2, p. 55

BRASIL. MINISTÉRIO DA PESCA E AQUICULTURA. Coordenação Geral de Registro de Aquicultura/CGRA/Departamento de Registro da Pesca e Aquicultura (DRPA). Secretaria de Monitoramento e Controle (SEMOC). [Ofício n 50/2011] 26 out. 2011, Brasilia [para] São Paulo, Conselho Regional de Medicina Veterinária e Zootecnia. Assessoria Técnica de Medicina Veterinária (ATMV). [2011] 7 f. Resposta Encaminhamentos da Comissão Técnica de Aquicultura/CTA/CRMV-SP. Brasília, DF, 2011.

BRASIL. MINISTÉRIO DA PESCA E AQUICULTURA. Secretaria de Monitoramento e Controle (SEMOC). [Ofício n 272/2011] 21 out. 2011, Brasilia, DF [para] São Paulo, Conselho Regional de Medicina Veterinária e Zootecnia/Assessoria Técnica de Medicina Veterinária (ATMV). 2011. 4 f. Resposta Encaminhamentos da Comissão Técnica de Aquicultura/CTA/CRMV-SP. Brasília, DF, 2011.

BRASIL. MINISTÉRIO DA PESCA E AQUICULTURA. MINISTÉRIO DA AGRICULTURA PECUÁRIA E ABASTECIMENTO. Extrato de Acordo de Cooperação Técnica n ${ }^{\circ} 6 / 2010$ Diário Oficial \{da\} República Federativa do Brasil. Brasilia, DF, 02 ago. 2010. Seção. 3 , p. 85.

BRASIL. MINISTÉRIO DA PESCA E AQUICULTURA. MINISTÉRIO DO MEIO AMBIENTE. Instrução Normativa Interministerial $n^{\circ} 1$, de 3 jan. 2012. Estabelece normas, critérios e padrões para a explotação de peixes nativos ou exóticos de águas continentais com finalidade ornamental ou de aquariofilia. Diário Oficial \{da\} República Federativa do Brasil. Brasília, DF, 4 jan. 2012. Seção. 1, p. 26-42.

BRASIL. MINISTÉRIO DO MEIO AMBIENTE. Instrução Normativa n 13 , de 09 de junho de 2005. Permitir, para fins ornamentais e de aquariofilia, a captura, o transporte e a comercialização de exemplares vivos de peixes nativos de águas continentais listados no Anexo I desta Instrução Normativa. Diário Oficial \{da\} República Federativa do Brasil. Brasília, DF, 13 jun. 2005. Seção. 1, p. 83

CRUZ, G. R. Gestão pública participativa: o papel da reforma do Estado e dos movimentos sociais. Revista de Ciência Política, São Carlos, n. 38, 2008. Disponível em: <http://www. achegas.net/numero/38/gisele_38.pdf>. Acesso em: 12 ago. 2012.
IBAMA. INSTITUTO BRASILEIRO DO MEIO AMBIENTE E DOS RECURSOS NATURAIS RENOVÁVEIS. Diagnóstico geral das práticas de controle ligadas a exploração, captura, comercialização, exportação e uso de peixes para fins ornamentais e de aquariofilia. Brasilia, DF, 2007. 214 p.

IBAMA. INSTITUTO BRASILEIRO DO MEIO AMBIENTE E DOS RECURSOS NATURAIS RENOVÁVEIS. Instrução Normativa $n^{\circ} 89$, de 02 de fevereiro de 2006. Define critérios para a exploração, a explotação, o transporte e a comercialização, inclusive a revenda, de algas marinhas do litoral brasileiro. Diário Oficial \{da\} República Federativa do Brasil. Brasilia, DF, 3 fev. 2006. Seção. 1, p. 109-110.

IBAMA. INSTITUTO BRASILEIRO DO MEIO AMBIENTE E DOS RECURSOS NATURAIS RENOVÁVEIS. Instrução Normativa $n^{\circ} 202$, de 22 de outubro de 2008. Dispõe sobre normas, critérios e padrões para a explotação com finalidade ornamental e de aquariofilia de peixes nativos ou exóticos de águas marinhas e estuarinas. Diário Oficial \{da\} República Federativa do Brasil. Brasilia, DF, 24 de out. 2008. Seção. 1 p. 82.

LIMA, A. O.; BERNARDINO, G.; PROENÇA, C. E. M. Agronegócio de peixes ornamentais no Brasil e no mundo. Revista Panorama da Aquicultura, Rio de Jameiro, v. 11, p. 14-24, 2001.

RIBEIRO, F. A. S. Panorama mundial do mercado de peixes ornamentais. Revista Panorama da Aquicultura, Rio de Janeiro, v. 108, p. 32-37, 2008.

RIBEIRO, F. A. S.; LIMA, M. T.; FERNANDES, J. B. K. Panorama do mercado de organismos aquáticos ornamentais. Boletim ABLimno, Rio Claro, v. 2, n. 38, 2010.

SÃO PAULO. (Estado). CONSELHO REGIONAL DE MEDICINA VETERINÁRIA E ZOOTECNIA. Assessoria Técnica de Medicina Veterinária (ATMV). [Ofício nº 429/2011] 29 jul. 2011, São Paulo [para] Ministério da Pesca e Aquicultura. Departamento de Registro da Pesca e Aquicultura (DRPA). Brasilia, DF. 12 f. Memórias da Organização doWorkshop "Gestão Participativa no Comércio de Peixes Ornamentais". São Paulo, SP, 2011.

SÃO PAULO (Estado). Decreto n 40.400, de 24 de outubro de 1995. Aprova Norma Técnica Especial relativa à instalação de estabelecimentos veterinários. Diário Oficial \{do\} Estado de São Paulo. São Paulo, SP, 25 de out. 1995. v. 105, n. 204.

VIDAL, M. V. As Boas perspectivas para a piscicultura ornamental. Revista Panorama da Aquicultura, Rio de Janeiro, v. 12, p. 41-45, 2002. 